\title{
The Effect of Chromium Addition and Heat Treatment on Phase Composition of Cast FeAISi Alloys
}

\author{
Martin Švec, Věra, Vodičková, Vojtěch Keller, Pavel Hanus \\ Department of Material Science, Technical University of Liberec, Studentská 2, 46117 Liberec 1, Czech Republic, E- \\ mail: martin.svec@tul.cz, ${ }^{2}$ vera.vodickova@tul.cz, ${ }^{3}$ vojtech.keller@tul.cz, ${ }^{4}$ pavel.hanus@tul.cz
}

\begin{abstract}
A structural studies have been performed on Fe-Al-Si iron aluminides with or without addition of chromium prepared by standard cast process. The effect of chromium addition and subsequent annealing on the phase composition was studied. Very fine precipitates were observed on the grain boundaries in the alloy without chromium addition. On the other hand, complex chromium carbides formed in the structure of chromium doped alloy. The annealing of alloy without $\mathrm{Cr}$ addition leads to partial dissolution of secondary phase particles. Unlike the chromium-doped alloy, where the secondary phase coarsed during the annealing process.

The phase composition of the alloys was studied by means of scanning electron microscopy (SEM) equipped by energy dispersive X-ray spectrometer (EDX). The electron backscattered diffraction (EBSD) was used for phase verification.
\end{abstract}

Keywords: $\mathrm{Fe}_{3} \mathrm{Al}$ - type iron aluminides, silicon addition, phase structure, heat-treatment

\section{Introduction}

Iron-aluminium intermetallic alloys are considered as promising candidates for structural applications [1], because of their lower density (about two thirds of the density of steels) as well as their excellent resistance to oxidation and sulfidation. On the other hand, some alloying elements as $\mathrm{Zr}$ f.e. decrease corrosion resistance significantly [2]. Moreover, the input raw materials are relatively cheap, so their affordability is an important attribute for industrial use. Generally, the mechanical, physical, fabrication, and corrosion properties of iron aluminides are very sensitive to alloying elements, so some disadvantageous properties (bad workability at room temperature or low high-temperature strength) can be improved by using alloying elements. For example, niobium or zirconium addition strengthen the matrix by incoherent precipitates primarily $[3,4]$, while chromium or silicon addition strengthen the matrix mostly by solid solution strengthening.

Silicon can be used for an improvement of the hightemperature tensile and creep strengths in all iron aluminide composition. Silicon also has been reported to increase the oxidation resistance [5].

At first, the ternary system Fe-Al-Si was studied from point of view $\mathrm{Fe}$ and $\mathrm{Si}$ as the most common impurities in aluminium alloys, subsequently it was also studied in the context of iron aluminide-based materials [6,7]. The system is characterized by a large number of binary and ternary phases, both stable and metastable. The presence of phases affects the mechanical properties, corrosion resistance, magnetic properties, etc. The ternary system FeAl-Si was investigated by [8] concerning the microstructure of binary and ternary phases in the temperature range between $600^{\circ} \mathrm{C}$ and $900^{\circ} \mathrm{C}$. The identification of nine ternary $\tau$ - phases as well as some binary phases (with low solubility of silicon) was verified in this system.

Recently the system was reinvestigated for two isothermal sections and six vertical sections by [9]. The new phase $\tau_{12}$ was found to be stable between $720^{\circ} \mathrm{C}$ and $1005^{\circ} \mathrm{C}$. The characterization of some phases was specified.

There exists also a limited knowledge about mechanical properties at higher temperature as well as about resistance against environment. The existing microstructure and mechanical properties investigations are connected with alloys produced by special technologies - by reactive sintering especially - or with alloys with composition corresponding to "Al-rich" corner.

The formation of intermediary phases during reactive sintering of $\mathrm{Fe}-\mathrm{Al}-\mathrm{Si}$ powder mixtures at $1100^{\circ} \mathrm{C}$ was studied in [10]. The hardness and abrasive wear resistance of alloys with different contents $\mathrm{Al}$ and $\mathrm{Si}$ were measured. The microstructure, phase composition and thermal stability of Al-Si-Fe-X alloys (with composition in Al-rich corner of ternary diagram) prepared by melt spinning process and Spark Plasma Sintering were recently investigated by [11]. Oxidation resistance of Fe-Al-Si alloys containing $10-30 \mathrm{wt}$. \% of aluminium and 5-30 wt. \% of silicon produced by the reactive sintering technology was tested by [12].

As described above, Fe-Al-Si alloys studied in [1014] were produced by costly and technologically demanding method of reactive sintering or their chemical composition was near to $\mathrm{Al}$ corner in ternary diagram. The aim of this article is the structure description of the competitive alloy with $\mathrm{Fe} 3 \mathrm{Al}$ matrix that can be made using a technologically easier casting process.

\section{Experimental methods}

The investigated alloys were prepared by vacuum induction melting and casting. The nominal chemical composition, labelling of the samples and their states are given in Tab. 1. Two alloys were studied - iron aluminide doped with silicon only and with combination of silicon and chromium. The raw iron with carbon content lower than 0.2 at. \% ("Arema") was used for casting.

The samples for study of microstructure were oxidepolishing by the suspension OP-S only. The structure was observed by light optical microscopy (LOM) Nikon - 
Epiphot, scanning electron microscopy (SEM) Tescan Vega SB equipped with Oxford X-Max20 detector for energy dispersive analysis (EDX) and by SEM Zeiss Ultra Plus equipped with Oxford X-Max20 EDX detector and Nordlys Nano EBSD detector. EBSD measurements were performed at accelerating voltage $20 \mathrm{kV}$. EBSD data were acquired using AZtec SW and processed in Chanell5 SW.

Heat treatment was performed in the furnace without a protection atmosphere (air heat treatment). The effect of short-term (24 hours) as well as long-term (100 hours) annealing on the phase stability at $1000^{\circ} \mathrm{C}$ were studied.

Tab. 1 The nominal chemical composition and the states of investigated samples

\begin{tabular}{|c|c|c|c|c|c|}
\hline \multirow{2}{*}{ sample } & \multicolumn{4}{|c|}{ chemical composition [at.\%] } & \multirow{2}{*}{ state } \\
\hline & $\mathbf{F e}$ & Al & Si & $\mathrm{Cr}$ & \\
\hline FA10Si as cast & bal. & 28.0 & 10.0 & - & As cast state \\
\hline FA10Si 1000 24 & $-"-$ & $-{ }^{\prime \prime}-$ & $-"-$ & $-"-$ & As cast state $\rightarrow$ annealed at $1000^{\circ} \mathrm{C}$ for 24 hours \\
\hline FA10Si 1000_100 & $-"-$ & $-{ }^{\prime \prime}-$ & $-"-$ & -"- & As cast state $\rightarrow$ annealed at $1000^{\circ} \mathrm{C}$ for 100 hours \\
\hline FA10Si3Cr as cast & bal. & 26.1 & 10.0 & 3.5 & As cast state \\
\hline $\begin{array}{c}\text { FA10Si3Cr } \\
1000 \_24\end{array}$ & $-"-$ & $-"-$ & $-"-$ & $-"-$ & As cast state $\rightarrow$ annealed at $1000^{\circ} \mathrm{C}$ for 24 hours \\
\hline $\begin{array}{c}\text { FA10Si3Cr } \\
1000 \_100\end{array}$ & $-"-$ & $-"-$ & $-"-$ & -"一 & As cast state $\rightarrow$ annealed at $1000^{\circ} \mathrm{C}$ for 100 hours \\
\hline
\end{tabular}

\section{Results and discussion}

The structure of alloys with the same silicon content (differing in chromium content) was studied in "as cast" state as well as after heat treatment. The effect of shortand long-term annealing on phase composition was investigated. Light optical microscopy was used to the structure preview, scanning electron microscopy with EDX and EBSD analysis was used to determine and verify the phase composition.

\subsection{Structure of FA10Si as cast}

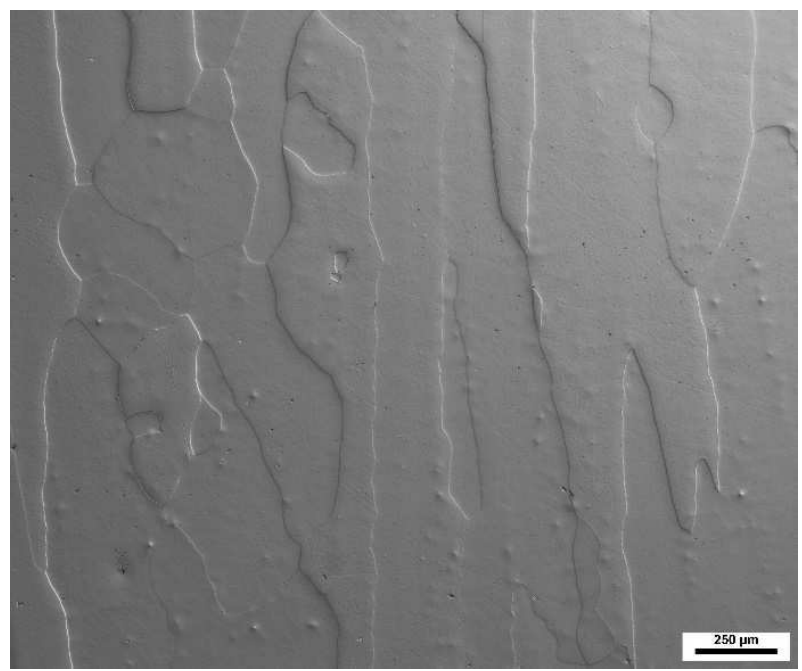

Fig. 1 The structure of alloy FA10Si as cast (LOM, Mag. 50x)

The structure of "FA10Si as cast" sample was coarsegrained. The dimensions of individual grains were in order of hundreds of micrometers (see Fig. 1), there were also elongated grains with length in order of units of millimeters locally. Fine particles (with thickness about $10-$ $20 \mathrm{~nm}$ ) were observed along grain boundaries (see Fig. 2). These precipitates were preliminary identified as carbides by EDX analysis. The presence of silicon in these particles has not been proven. According to EDX analysis results these particles might be perovskite-type. Very fine needle-like particles (with dimensions under EDX resolution) were also observed randomly inside the grains (Fig. 2). Silicon was dissolved into the matrix (according to the results of EDX measurement), in agreement with Fe-Al-Si ternary diagram.

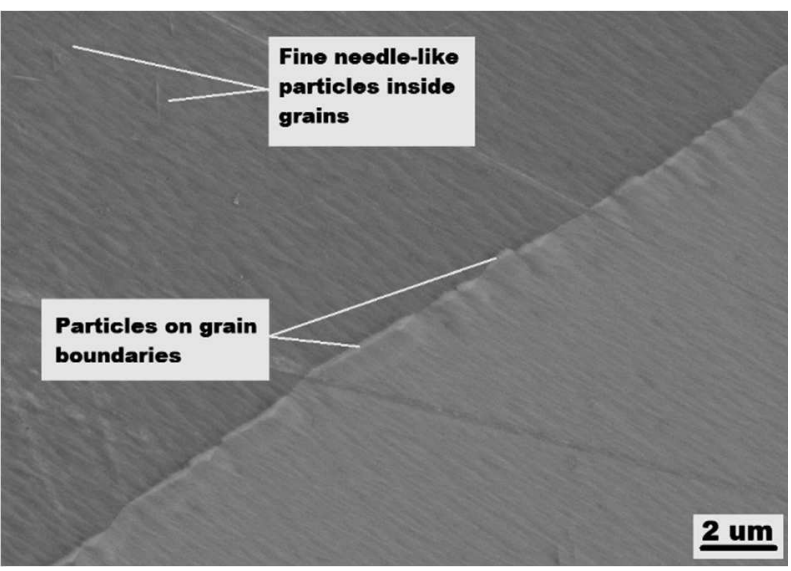

Fig. 2 The detail of structure of alloy FA10Si as cast (SEM)

\subsection{Structure of FA10Si after heat treatment}

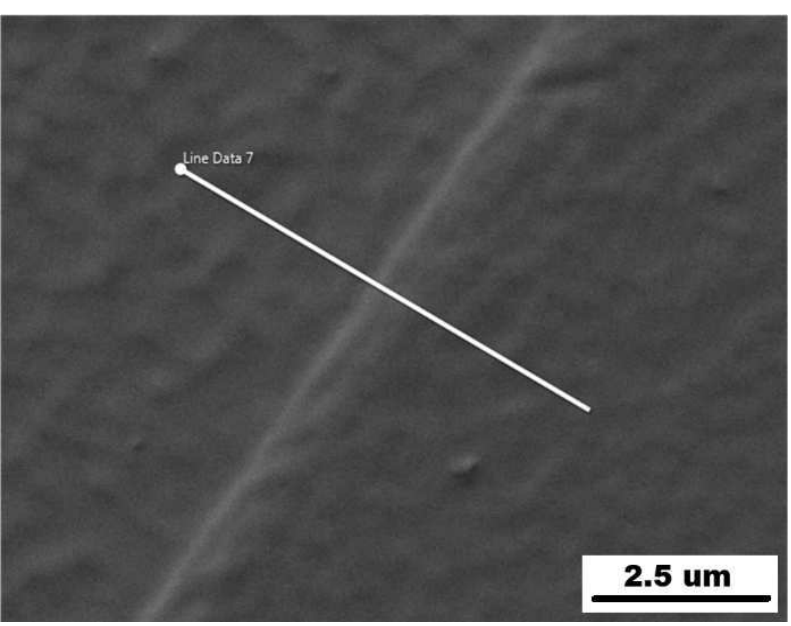

Fig. 3 The detail of particle on grain boundary in alloy FA10Si 1000_24 (SEM) 
The short-term annealing ( 24 hours) led to partly dissolution of particles along grain boundaries. The very fine needle-like precipitates inside the grains were completely dissolved (Fig. 3). The influence of the long-term annealing (100 hours) on the phase stability was evident (see Fig. 4) - particles along grain boundaries were completely dissolved. Therefore, it can be supposed, that the structure is composed of solid solution of Fe-Al-Si after long-term annealing only.

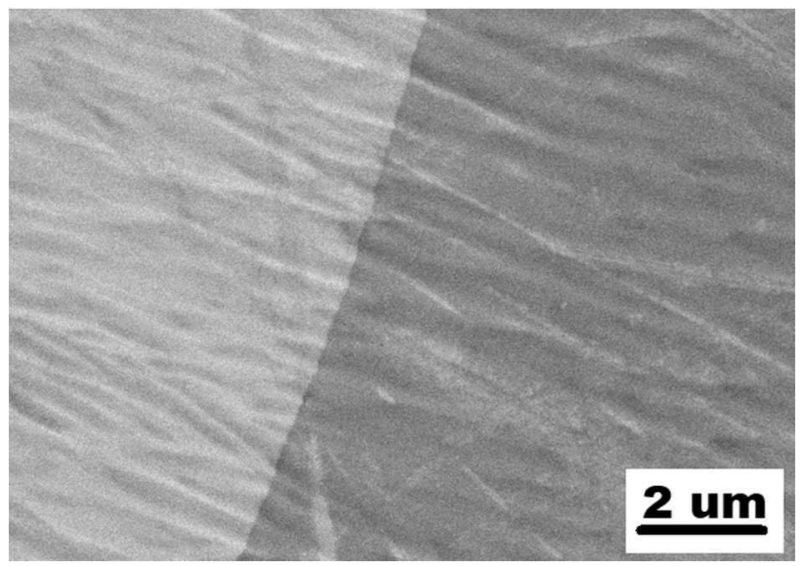

Fig. 4 The detail of grain boundary in alloy FA10Si 1000100 (SEM)

\subsection{Structure of FA10Si3Cr as cast}

The shape and dimensions of grains in $\mathrm{FA} 10 \mathrm{Si} 3 \mathrm{Cr}$ were comparable with the previous alloy FA10Si. Different types of precipitates formed in the structure of FA10Si3Cr alloy due to addition of chromium (see Fig. 5). Individual particles (see "Particle 1" and "Particle 2" marked in Fig. 5) with similar chemical composition were observed inside the grains. These particles differed with content of chromium - the chromium content in "Particle 2 "-type is twofold compared to "Particle 1"-type. The silicon content in composition comes from the matrix very probably. The eutectic marked as "Particle 3" in Fig. 5 was composed of $\mathrm{Fe}-\mathrm{Al}$ matrix and chromium carbide or complex carbide $\mathrm{Fe}-\mathrm{Cr}-\mathrm{C}$. A more accurate identification by means of EDX or EBSD methods was not possible due to small size of these particles. On the other hand, the size and way of distribution (along the grain boundaries) of particles could be advantageous for grain boundary reinforcement.

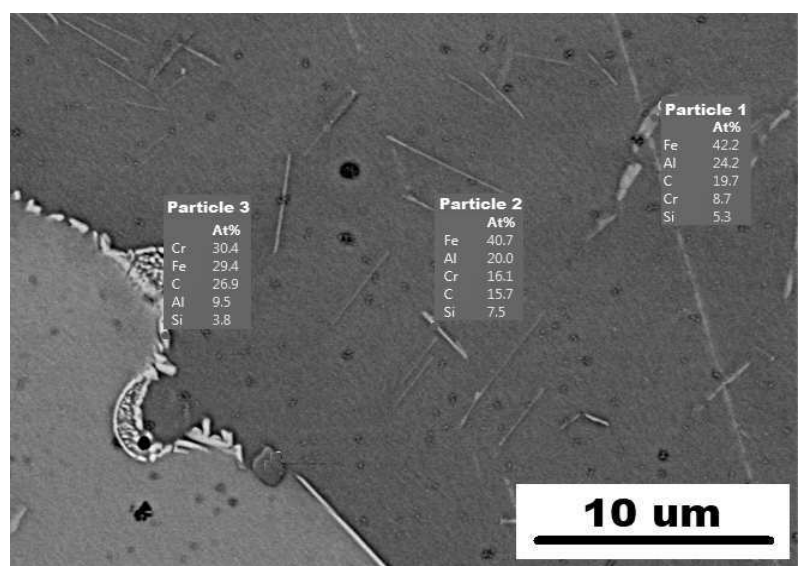

Fig. 5 The detail of structure of alloy FA10Si3Cr as cast (SEM)
There is no chromium dissolved in the matrix according to $\mathrm{Fe}-\mathrm{Al}-\mathrm{Cr}$ diagram in the case of present alloy due to higher chromium affinity to carbon (coming from Arema). In contrast with Fe-Al-Nb-Cr alloy [15], where carbon reacts preferably with niobium, therefore, chromium remains for solid solution strengthening. This mechanism could have higher potential for alloy strengthening (strengthening by $\mathrm{NbC}$ precipitates and solid solution strengthening by $\mathrm{Cr}$ ).

\subsection{Structure of FA10Si3Cr after heat treatment}

The residues of eutectic mixture were completely dissolved after short-term (see Fig. 6) as well as after longterm (see Fig. 7) annealing. The individual precipitates coarsened during heat treatment. This coarsening is more pronounced in the case of long-term annealing (see Fig. 7). EDX map of FA10Si3Cr 1000_24 sample in Fig. 8 shows, that the precipitates are chromium carbides probably (compare map for $\mathrm{C}$ and $\mathrm{Cr}$ ). The same particles were observed also after long-term annealing (sample FA10Si3Cr 1000_100) - see EDX line scan in Fig. 9. These precipitates were coarser; therefore, they were suitable for phase identification by EBSD. EBSD measurement (see Kikuchi bands of FA10Si3Cr 1000_100 sample in Fig. 10) shows that these precipitates are cubic complex carbides $\mathrm{Cr}_{19} \mathrm{Fe}_{4} \mathrm{C}_{6}$. These precipitates border grain boundaries densely again, but their share on reinforcement of boundaries will be not so significant due to the coarsening.

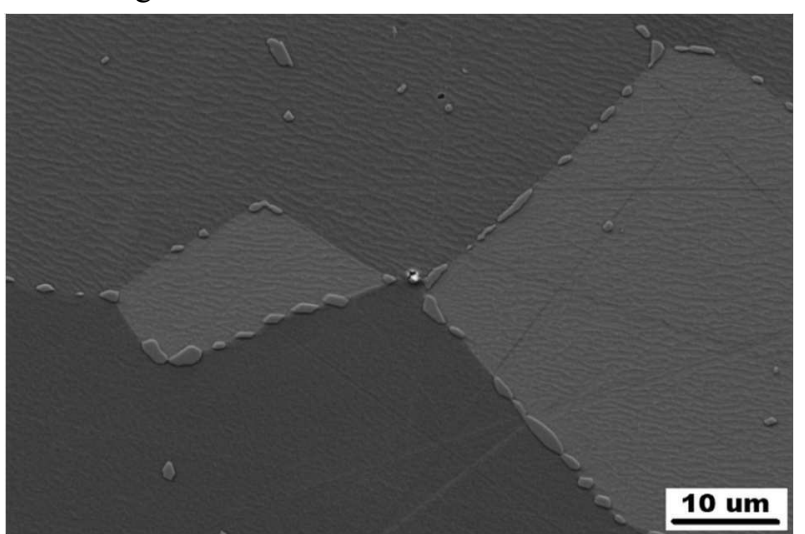

Fig. 6 The structure of alloy FA10Si3Cr 100024 (SEM)

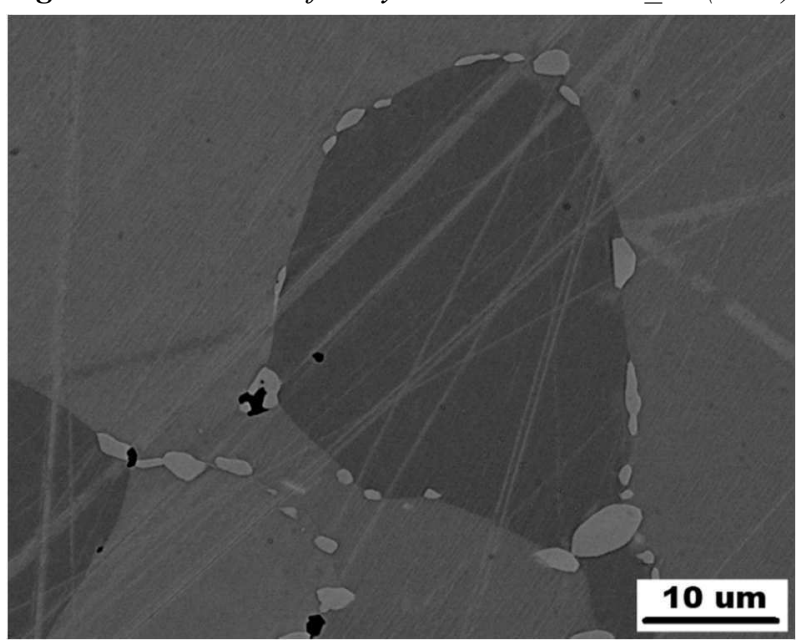

Fig. 7 The structure of alloy FA10Si3Cr 1000_100 (SEM) 

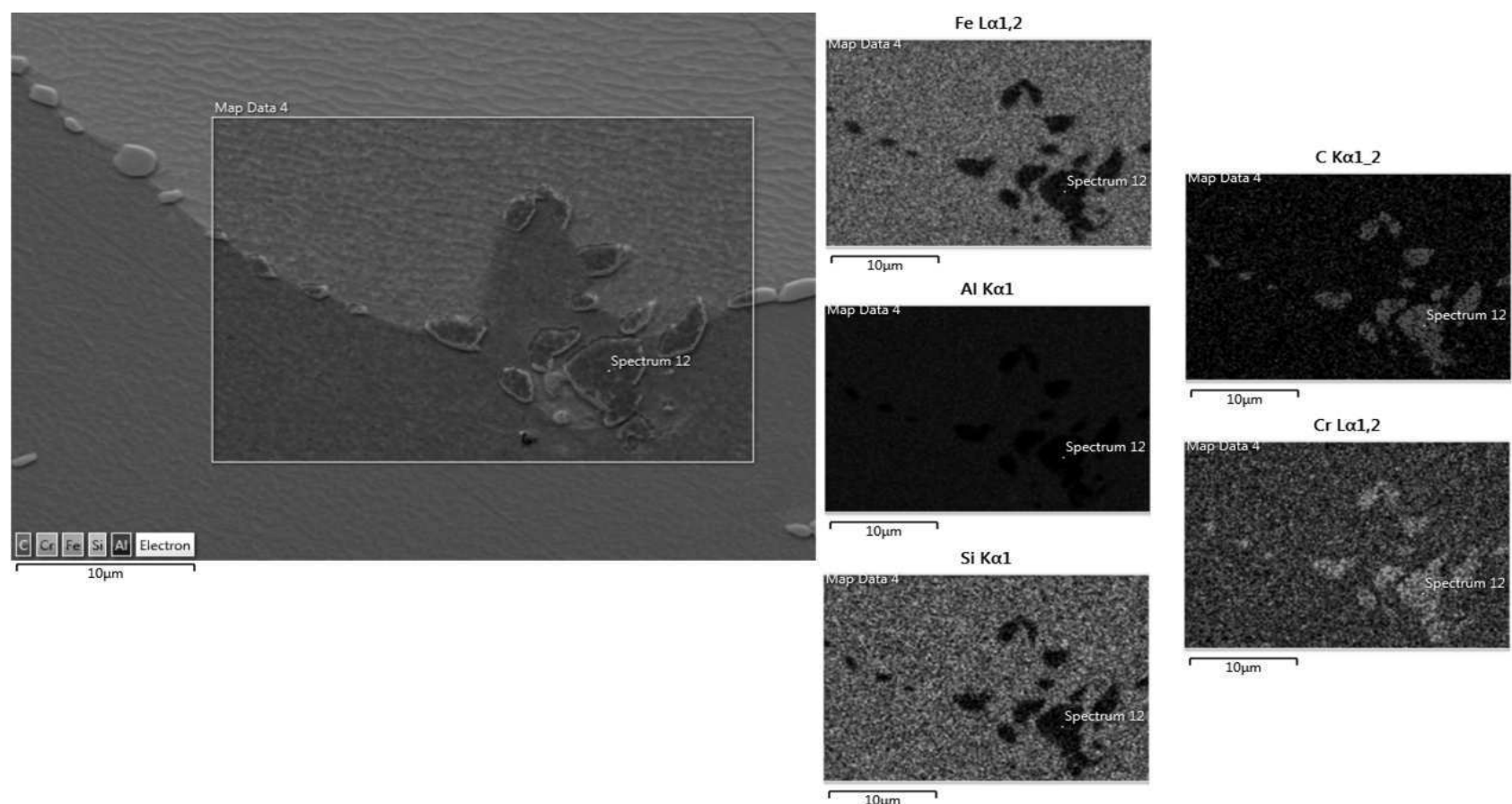

Fig. 8 EDX map of matrix and precipitates of alloy FA10Si3Cr 1000_24 (SEM)
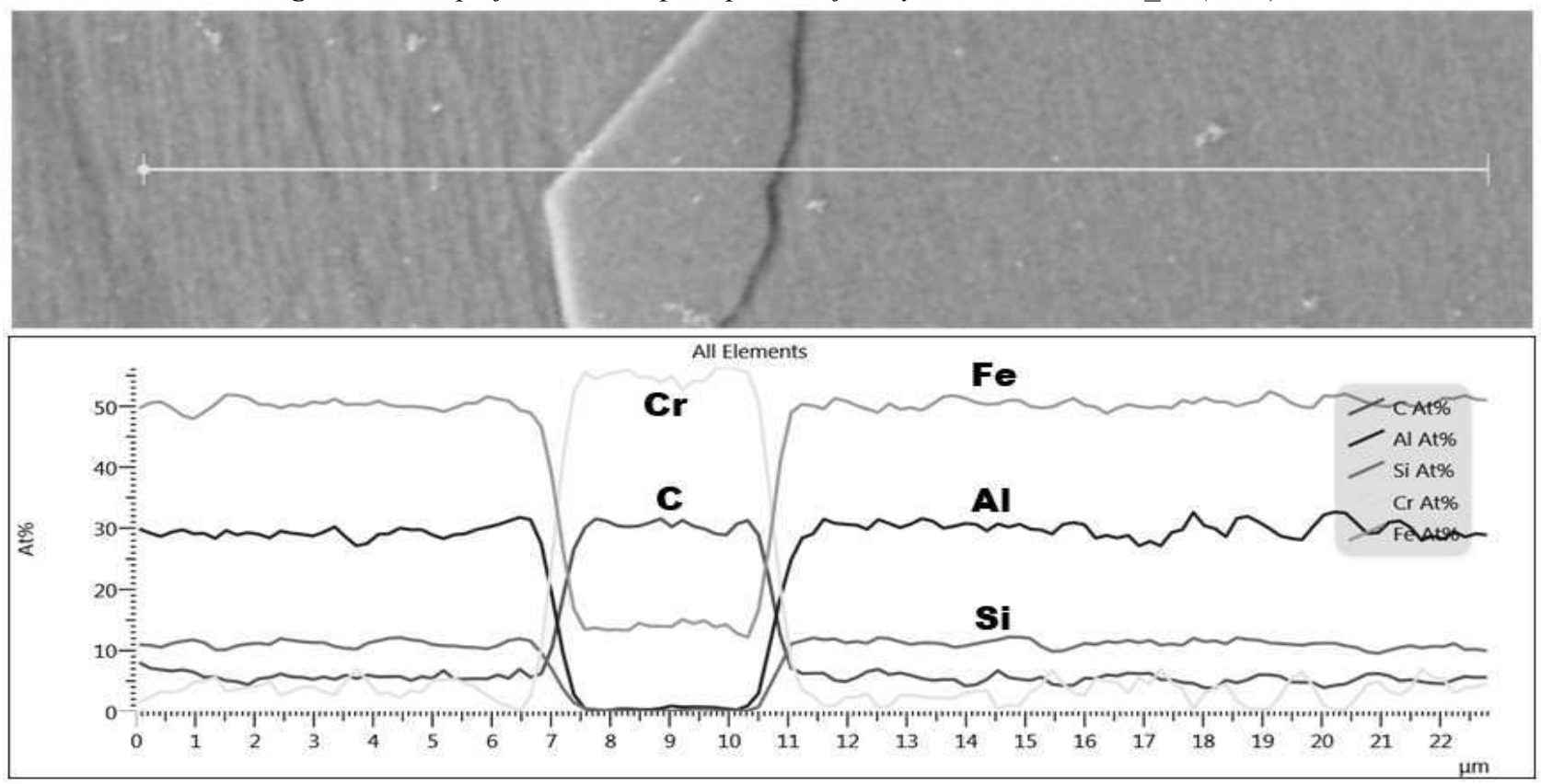

Fig. 9 EDX line scan analysis through precipitate in alloy FA10Si3Cr 1000_100 (SEM)
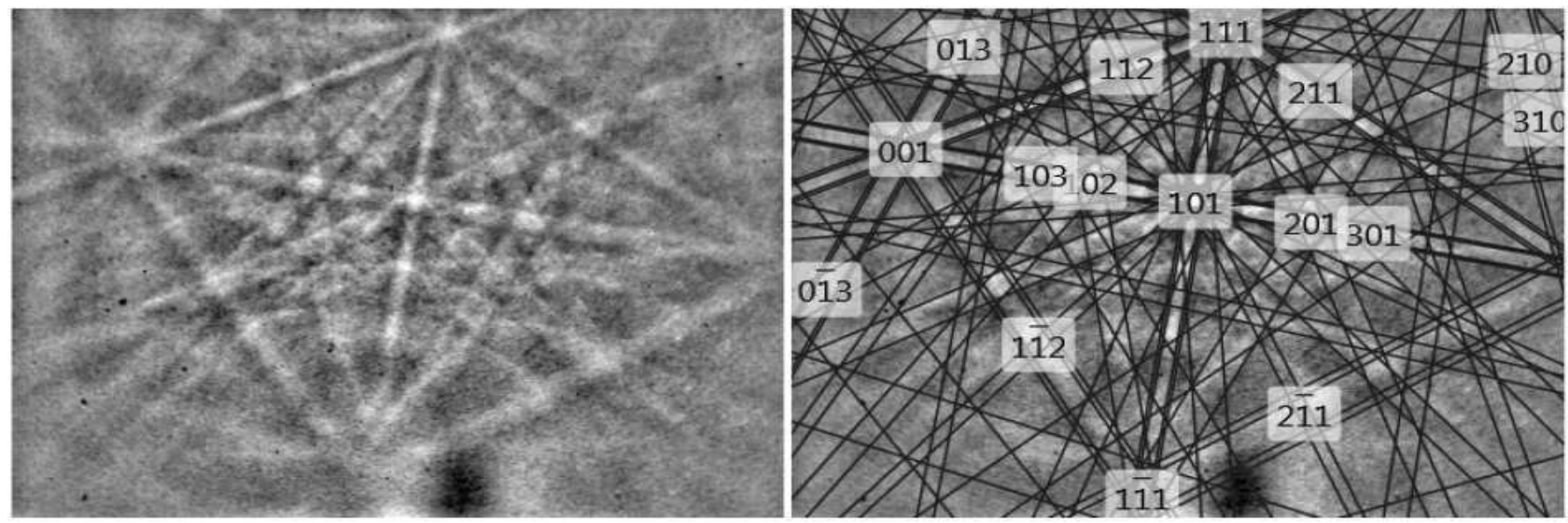

Fig. 10 EBSD Kikuchi bands of precipitate in Fig. 9 (alloy FA10Si3Cr 1000_100) 


\section{Conclusion}

Very fine non specified (due to their very small sizes) precipitates were observed on the grain boundaries in the alloy without chromium addition. On the other hand, complex chromium carbides $\mathrm{Cr}_{19} \mathrm{Fe}_{4} \mathrm{C}_{6}$ formed in the structure of chromium doped alloy. More detailed study using TEM should be done to identify small particles.

The short-annealing of alloy without $\mathrm{Cr}$ addition leads to partial dissolution of secondary phase particles, the dissolution continues during long-term annealing. Unlike this, the secondary phases in the chromium-doped alloy were more stable and they were getting coarsen during both type of annealing.

The purity of raw materials should be supervised during casting of $\mathrm{Fe}-\mathrm{Al}-\mathrm{Si}-\mathrm{Cr}$ alloys. Especially, the presence of carbon affects the secondary phase formation due to the high affinity of carbon to alloying elements.

\section{Acknowledgment}

This work was supported by the Ministry of Education, Youth and Sports of the Czech Republic and the European Union - European Structural and Investment Funds in the frames of Operational Programme Research, Development and Education - project Hybrid Materials for Hierarchical Structures (HyHi, Reg. No. CZ.02.1.01/0.0/0.0/16_019/0000843).

\section{References}

[1] STOLOFF, N. S., LIU, C. T., DEEVI, S. C. (2001). Emerging applications of intermetallics. In: Intermetallics, Vol. 8, pp. 1313 - 1320. Netherlands.

[2] HOTǍ̆, A., KEJZLAR, P., PALM, M. MLNAŘíK, J. (2015). The effect of Zr on hightemperature oxidation behavior of $\mathrm{Fe}_{3} \mathrm{Al}$-based alloys. In: Corrosion Science, Vol. 100, pp. $147-$ 157. United Kingdom.

[3] KEJZLAR, P. (2012). Structure and mechanical properties of $\mathrm{Fe}-25 \mathrm{Al}-5 \mathrm{Zr}$ and $\mathrm{Fe}-30 \mathrm{Al}-5 \mathrm{Zr}$ intermetallic alloys. In: Manufacturing Technology, Vol. 12, No. 13, pp. 131 - 135. Ústí nad Labem Czech Republic.

[4] ŠVEC, M., VODIČKOVÁ, V. (2014). The effect of niobium addition and heat treatment on the phase structure of $\mathrm{Fe}_{3} \mathrm{Al}$ - type intermetallic alloys. In: Manufacturing Technology, Vol. 14, No. 3, pp. 456 - 461. Ústí nad Labem - Czech Republic.

[5] MC KAMEY, C. G. (1994). Iron Aluminides. In: Physical Metalurgy and processing of Intermetallic Compounds, pp. 375 - 380. Springer Verlag, Berlin - Germany.
[6] GHOSH G. (1992). Ternary alloys 5, pp. $394-$ 437. VCH Publisher, Weinheim - Germany.

[7] GHOSH G. (2005). Aluminium - iron - silicon, light metal systems: phase diagrams, crystallographic and thermodynamic data, pp. $359-409$. Springer Verlag, Berlin - Germany.

[8] MAITRA T., GUPTA S. P. (2003). Intermetallic compound formation in $\mathrm{Fe}-\mathrm{Al}$ - Si ternary system: Part II. In: Materials Characterization, Vol. 49, pp. 293 - 311. Netherlands.

[9] MARKER M., SKOLYSZEWSKAKÜHBERGER B., EFFENBERGER H.S., SCHMETTERER C., RICHTER K.W. (2011). Phase equilibria and structural investigations in the system Al-Fe-Si. In: Intermetallics, Vol. 19, pp. 1919 - 1929. Netherlands.

[10] NOVÁK P., KNOTEK V., VODĚROVÁ M., KUBÁSEK J., ŠERÁK J., MICHALCOVÁ A., VOJTĚCH D. (2010). Intermediary phases formation in $\mathrm{Fe}-\mathrm{Al}-\mathrm{Si}$ alloys during reactive sintering. In: Journal of Alloys and Compounds, Vol. 497, pp. 90 - 94. Netherlands.

[11] ŠKOLÁKOVÁ A., NOVÁK P., VOJTĚCH D., KUBATÍK T. (2016). Microstructure and mechanical properties of $\mathrm{Al}-\mathrm{Si}-\mathrm{Fe}-\mathrm{X}$ alloys. In: $\mathrm{Ma}-$ terials and Design, Vol. 107, pp. 491-502. Netherlands.

[12] NOVÁK P., ZELINKOVÁ M., ŠERÁK J., MICHALCOVÁ A., NOVÁK M., VOJTĚCH D. (2011). Oxidation resistance of SHS Fe-Al-Si alloys at $800^{\circ} \mathrm{C}$ in air. In: Intermetallics, Vol. 19, pp. 1306 - 1312. Netherlands.

[13] NOVÁ K., NOVÁK P., VANKA T., PRŮŠA F. (2018). The Effect of Production Process on Properties of FeAl20Si20. In: Manufacturing Technology, Vol. 18, No. 2, pp. 295 - 298. Ústí nad Labem - Czech Republic.

[14] NOVÁK P., NOVÁ K., VANKA T., PRŮŠA F. (2018). High-temperature Behaviour of New FeAl-Si Alloy Produced by Powder Metallurgy. In: Manufacturing Technology, Vol. 18, No. 2, pp. 299 - 302. Ústí nad Labem - Czech Republic.

[15] ŠVEC M., VODIČKOVÁ V., HANUS P. (2012). The effect of heat treatment on the structure of $\mathrm{Nb}$ and $\mathrm{Cr}$ doped $\mathrm{Fe}_{3} \mathrm{Al}$ alloy. In: Proceedings of 21 st International Conference on Metallurgy and Materials, 502.pdf. Tanger. Ostrava - Czech Republic. 